\title{
A molecular endless (74) knot
}

DOI:

10.1038/s41557-020-00594-x

\section{Document Version}

Accepted author manuscript

Link to publication record in Manchester Research Explorer

\section{Citation for published version (APA):}

Leigh, D., Danon, J., Fielden, S., Lemonnier, J-F., Whitehead, G., \& Woltering, S. (2020). A molecular endless $\left(7_{4}\right)$ knot. Nature Chemistry, O(0), 0. [0]. https://doi.org/10.1038/s41557-020-00594-x

\section{Published in:}

Nature Chemistry

\section{Citing this paper}

Please note that where the full-text provided on Manchester Research Explorer is the Author Accepted Manuscript or Proof version this may differ from the final Published version. If citing, it is advised that you check and use the publisher's definitive version.

\section{General rights}

Copyright and moral rights for the publications made accessible in the Research Explorer are retained by the authors and/or other copyright owners and it is a condition of accessing publications that users recognise and abide by the legal requirements associated with these rights.

\section{Takedown policy}

If you believe that this document breaches copyright please refer to the University of Manchester's Takedown Procedures [http://man.ac.uk/04Y6Bo] or contact uml.scholarlycommunications@manchester.ac.uk providing relevant details, so we can investigate your claim.

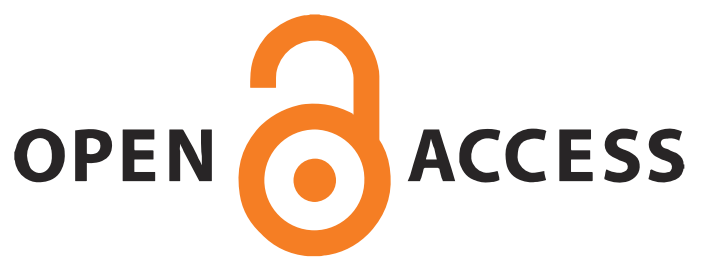




\title{
A molecular endless $\left(7_{4}\right)$ knot
}

\author{
David A. Leigh ${ }^{[a, b] *}$, Jonathan J. Danon ${ }^{[b]}$, Stephen D. P. Fielden ${ }^{[b]}$, Jean-François Lemonnier ${ }^{[b]}$, \\ George F. S. Whitehead ${ }^{[b]}$ and Steffen L. Woltering ${ }^{[b]}$ \\ ${ }^{[a]}$ School of Chemistry and Molecular Engineering, East China Normal University, 200062 Shanghai, \\ China \\ ${ }^{[b]}$ Department of Chemistry, University of Manchester, Oxford Road, Manchester M13 9PL, United \\ Kingdom \\ *Correspondence to: david.leigh@manchester.ac.uk
}

\begin{abstract}
Current strategies for the synthesis of molecular knots focus on twisting, folding and/or threading molecular building blocks. Here we report that $\mathrm{Zn}$ (II) or Fe(II) ions can be used to weave ligand strands to form a woven $3 \times 3$ molecular grid. We find that the process requires tetrafluoroborate anions to template the assembly of the interwoven grid by binding within the square cavities formed between the metal-coordinated criss-crossed ligands. The strand ends of the grid can subsequently be joined through within-grid alkene metathesis reactions to form a topologically-trivial macrocycle (unknot), a doubly-interlocked [2]catenane (Solomon link) and a knot with seven crossings in a 258-atom-long closed loop. This $7_{4}$ knot topology corresponds to that of the endless knot, which is a basic motif of Celtic interlace, the smallest Chinese knot and one of the eight auspicious symbols of Buddhism and Hinduism. The weaving of molecular strands within a discrete layer by anion template, metal ion coordination opens the way for the synthesis of other molecular knot topologies and to woven polymer materials.
\end{abstract}

Knots are fundamental elements of structure, exploited in basic tools and materials from shoelaces to fishing nets and woven fabrics. ${ }^{1}$ At the molecular level, knots ${ }^{2}$ form spontaneously in flexible polymer chains $^{3}$ and are found in DNA and $\sim 1 \%$ of proteins in the protein data bank (PDB) ${ }^{4}$. Molecular level knotting influences properties such as elasticity, ${ }^{5}$ tensile strength ${ }^{5}$ and the expression of chirality ${ }^{6}$ has been implicated in biological activity, ${ }^{4,7}$ and can assist the formation of precisely structured sites for binding $^{8,9}$ and catalysis ${ }^{10,11}$. Artificial molecular knots have been synthesised, sometimes unexpectedly, through the use of metal ion templates, ${ }^{12-20}$ covalent scaffolds, ${ }^{21}$ hydrogen bonding, ${ }^{22,23}$ coordination bonds ${ }^{24-26}$ and/or hydrophobic-driven folding ${ }^{27-29}$ to direct their assembly ${ }^{30-32}$. One of the most versatile routes to different molecular knots and links is based on cyclic helicate scaffolds, ${ }^{31}$ which twist two or three molecular threads about one another to generate strand crossings.

Simulations have identified 'privileged topologies' that are particularly accessible through such processes. ${ }^{33}$ However, such self-assembly approaches are currently limited to a few simple or torus knots and certain classes of composite knots. Here we report on the synthesis of a seven-crossing $\left(7_{4}\right.$ in Alexander-Briggs notation ${ }^{34}$ ) molecular knot (Fig. 1). ${ }^{35}$ It does not correspond to a previously identified privileged topology because it is prepared by a fundamentally different synthetic strategy: the use of metal ions to weave-rather than twist, fold or thread through a loop-molecular strands. A key intermediate in the formation of the knot is an interwoven $3 \times 3$ molecular grid, whose assembly depends on a specific anion to act as a template. Metal-ion coordination-driven two-dimensional weaving offers a route to new types of molecular knot topologies and woven molecular fabrics. 


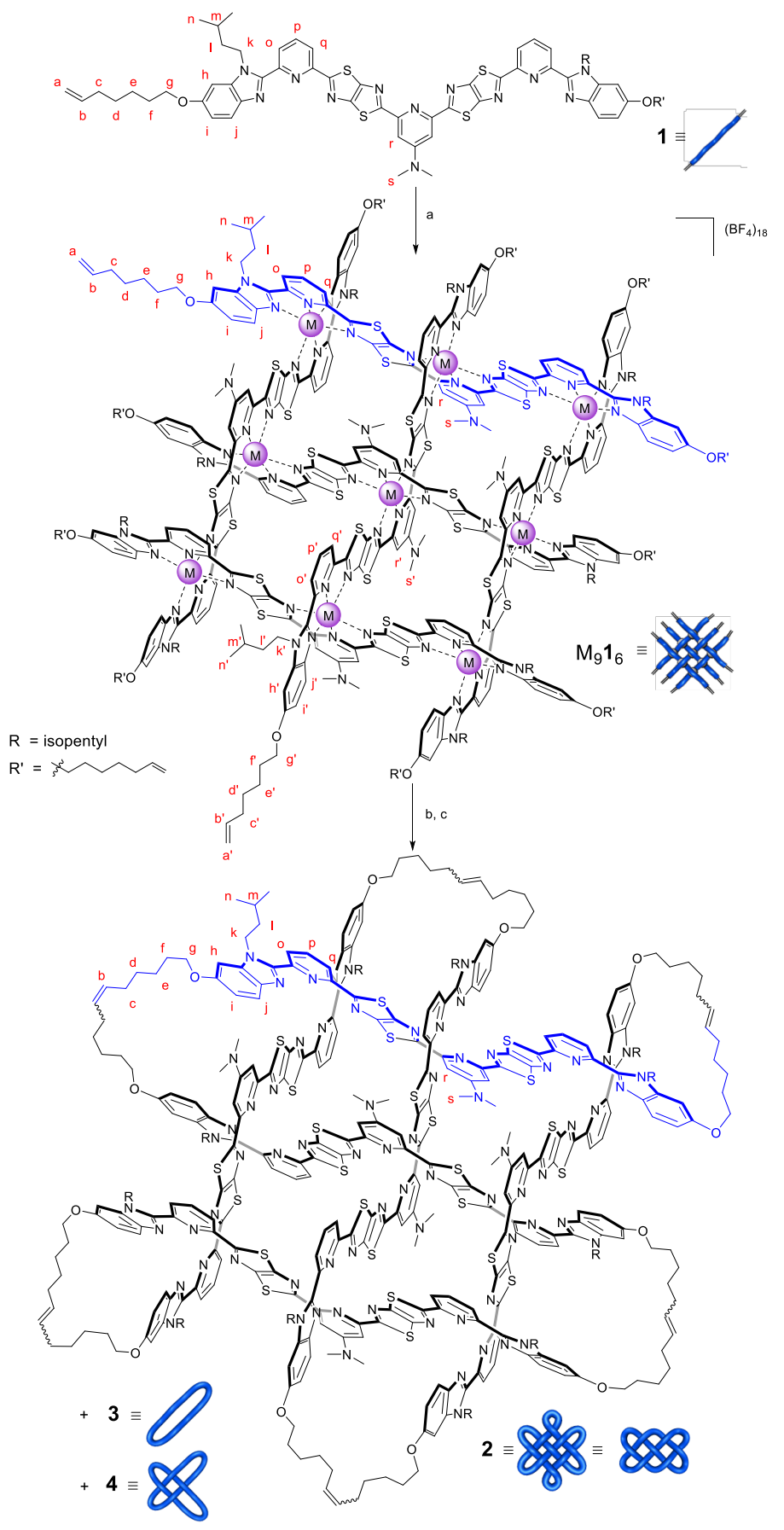

Fig. 1 Synthesis of interwoven $3 \times 3$ grids $\left[\mathrm{Zn}_{9} 1_{6}\right]\left(\mathrm{BF}_{4}\right)_{18}$ and $\left[\mathrm{Fe}_{9} 1_{6}\right]\left(\mathrm{BF}_{4}\right)_{18}$, macrocycle 3 , Solomon link 4 and $7_{4}$ knot 2 . The use of $\mathrm{BF}_{4}{ }^{-}$anions was found to be essential to form the $3 \times 3$ metal-coordinated grid. Subsequent ring-closing olefin metathesis followed by ion removal affords the wholly-organic ring, link and knot products. Reagents and conditions: i, 1.5 equivalents $\mathrm{M}\left(\mathrm{BF}_{4}\right)_{2} \cdot 6 \mathrm{H}_{2} \mathrm{O}(\mathrm{M}=\mathrm{Fe}(\mathrm{II})$ or $\mathrm{Zn}(\mathrm{II})), \mathrm{CH}_{3} \mathrm{CN} / \mathrm{CHCl}_{3} 1: 1$, rt, $5 \mathrm{~min}$ for $\mathrm{M}=\mathrm{Zn}(\mathrm{II})$ and $\mathrm{CH}_{3} \mathrm{CN} /$ toluene 5:3, $100{ }^{\circ} \mathrm{C}, 72 \mathrm{~h}$ for $\mathrm{Fe}(\mathrm{II}) ; 99 \%$ for $\left[\mathrm{Zn}_{9} \mathbf{1}_{6}\right]\left(\mathrm{BF}_{4}\right)_{18}, 97 \%$ for $\left[\mathrm{Fe}_{9} \mathbf{1}_{6}\right]\left(\mathrm{BF}_{4}\right)_{18} ; \mathrm{ii}, 2^{\text {nd }}$ Generation HoveydaGrubbs catalyst, 0.1 equiv. per alkene, $\mathrm{CH}_{2} \mathrm{Cl}_{2} / \mathrm{CH}_{3} \mathrm{NO}_{2} 3: 1,110^{\circ} \mathrm{C}$ (microwave irradiation), $1.5 \mathrm{~h}$; iii, $\mathrm{Li}_{2} \mathrm{~S}_{(\text {aq.) }}$ for $\mathrm{M}=\mathrm{Zn}(\mathrm{II}), \mathrm{Na}_{4} \mathrm{EDTA}_{\text {(aq.) }}$ for $\mathrm{M}=\mathrm{Fe}(\mathrm{II})$. Cyclic product distribution after step c: $\mathbf{2} 7 \%, 337$ $\%, 456 \%$.

Molecular grids that consist of stacked layers ${ }^{36,37}$ of criss-crossed metal-coordinated ligands have attracted attention as potential information storage materials. In contrast, molecular grids featuring interwoven (rather than stacked) ligand strands are unknown, other than the simplest, $2 \times 2$, arrangement, which does not have internal crossings. Reasons for the scarcity of such molecular 
architectures may be related to the consequences of strand rigidity: weaving requires more than just strands to cross one another; to create a mechanical entanglement every thread must pass over (at least) one thread, then under a subsequent one (or more), and then back over a third, returning to the original plane. In the macroscopic world wooden sticks can be woven into structures held together only by the pressure exerted between the sticks at the crossing points, but for a supramolecular assembly such stresses impose limitations and tolerances on metal-donor distances and geometries for internal coordination sites. We identified a strand design based upon thiazolo[5,4-d]thiazole (TTZ) units that we thought could minimize such strain. The TTZ moiety induces a zig-zag metal-ligand coordination motif where the metal centres align warp and weft ligand strands in an over-under pattern, the first part of a weave sequence. We previously used this basic unit for the synthesis of a Solomon link (a doublyinterlocked [2]catenane or $4^{2}{ }_{1}$ link) and a granny composite knot from $2 \times 2$ grids featuring strictly coplanar metal ions. ${ }^{38,39}$ Extending this motif to complete the weave (i.e., forming an over-under-over sequence) might be possible without imposing significant strain if the additional third (internal) coordination site of each ligand strand held the extra metal ions within the same plane as the others in the grid.

\section{Results and discussion}

We explored a number of designs based on this concept, varying the coordination environment (e.g. shape, geometry, bond lengths, angles, spacers, and electron donating ability of the donor atoms) of the internal and outer binding sites of each strand. In every case the new ligands could be coordinated to metal ions (our binding experiments typically used zinc(II) triflate $\left(\mathrm{Zn}(\mathrm{OTf})_{2}\right)$ in non-coordinating solvents, which worked well with our previous $2 \times 2$ grid-forming ligands), but none formed in a stoichiometry consistent with a $3 \times 3$ grid. Most of the designs appeared to bind metal ions only in the outer coordination sites of each strand (see Supplementary Information section 2.1 for a discussion of the evolution of the ligand design).

One strand design, 1, featured a TTZ group combined with a benzimidazole and pyridine unit for the two outer coordination sites and two TTZ motifs in combination with a 4-dimethylaminopyridine group at the inner site (Fig. 1). We envisaged that the electron donating ability of the 4-dimethylamino moiety should enhance the metal-ion-coordinating efficacy at this position, potentially sufficiently to overcome the stringent fit requirements necessary for the internal binding site. In preliminary coordination experiments of 1 with $\mathrm{Zn}(\mathrm{OTf})_{2}$ in acetonitrile and chloroform, a complex mixture of products formed, with ${ }^{1} \mathrm{H}$ nuclear magnetic resonance (NMR) spectroscopy and mass spectrometric evidence for the formation of various sized metal-coordinated oligomers and a square coordination complex (the outer framework of the grid). Recalling that the X-ray crystal structure of the Solomon link assembled from TTZ-based ligands had a well-ordered $\mathrm{BF}_{4}{ }_{4}$ anion positioned in the square cavity of the $2 \times 2 \mathrm{grid},{ }^{38}$ one of us (J.-F.L.) decided to repeat the coordination-driven assembly of 1 replacing $\mathrm{Zn}(\mathrm{OTf})_{2}$ with $\mathrm{Zn}\left(\mathrm{BF}_{4}\right)_{2}$. Remarkably, addition of 1.5 equivalents of $\mathrm{Zn}\left(\mathrm{BF}_{4}\right)_{2} \cdot 6 \mathrm{H}_{2} \mathrm{O}$ to 1 in chloroform/acetonitrile (1:1) led to the quantitative formation of a distinct coordination complex within 5 minutes, shown by Diffusion-Ordered ${ }^{1} \mathrm{H}$ NMR Spectroscopy (DOSY) to be a single species with a self-diffusion constant, $D$, of $2.9 \times 10^{-6}$ $\mathrm{cm}^{2} \mathrm{~s}^{-1}$, confirmed by mass spectrometry to have the formula $\left[\mathrm{Zn}_{9} \mathbf{1}_{6}\right]\left(\mathrm{BF}_{4}\right)_{18}$. The ${ }^{1} \mathrm{H}$ NMR spectrum of $\left[\mathrm{Zn}_{9} 1_{6}\right]\left(\mathrm{BF}_{4}\right)_{18}$ in $\mathrm{CD}_{3} \mathrm{CN}: \mathrm{CDCl}_{3}(1: 1)$ at $298 \mathrm{~K}$ (Fig. $\left.2 \mathrm{~b}\right)$ reveals it to have a highly symmetrical structure, with the six ligands of 1 occupying two different environments in a 2:1 ratio. This is consistent with a $3 \times 3$ interwoven grid $\left(D_{2 d}\right.$ symmetry) in which the four ligand strands of the exterior square are all chemically equivalent to each other, but are in a different environment to the two strands that make up the internal cross (which are also in mutually identical environments). 


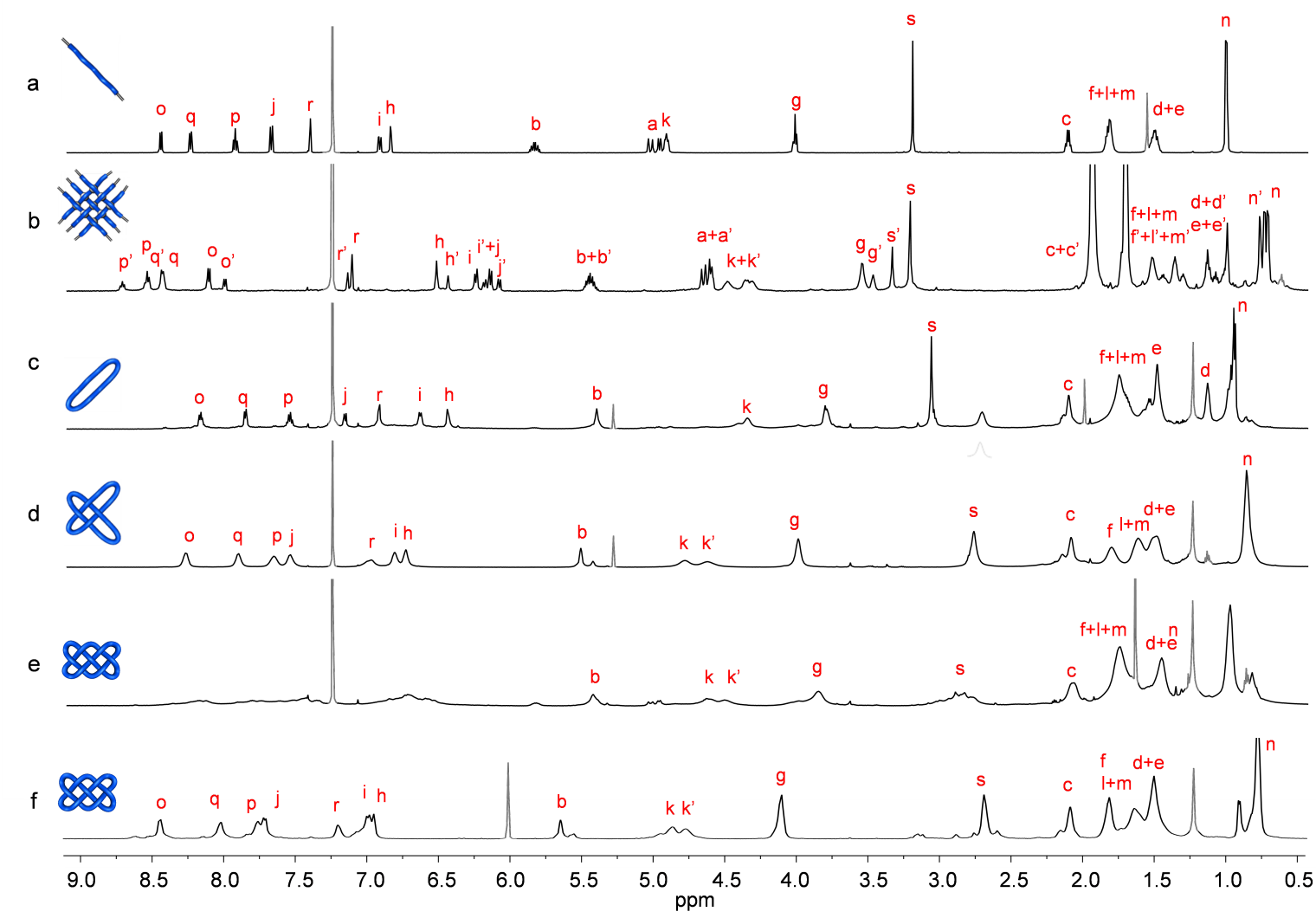

Fig. 2 | ${ }^{7} \mathrm{H}$ NMR spectra (600 MHz [except (f)], $298 \mathrm{~K}$ [except (f)]) of building block 1, metalcoordinated intermediate $\left[\mathrm{Zn}_{9} 1_{6}\right]\left(\mathrm{BF}_{4}\right)_{18}$, and ring-closed products 2-4. Note the broadening of the room temperature spectra (from (a) to (c) to (d) to (e)) as the structural complexity increases concomitantly with the time taken for each proton to sample the different environments available to it. (a) Ligand 1 in $\mathrm{CDCl}_{3}$; (b) $3 \times 3$ interwoven grid $\left[\mathrm{Zn}_{9} \mathbf{1}_{6}\right]\left(\mathrm{BF}_{4}\right)_{18}$ in $\mathrm{CD}_{3} \mathrm{CN}: \mathrm{CDCl}_{3}$ (1:1) (the grid is only sparingly soluble in pure $\mathrm{CDCl}_{3}$ ); (c) macrocycle 3 in $\mathrm{CDCl}_{3}$; (d) Solomon link 4 in $\mathrm{CDCl}_{3}$; (e) $7_{4}$ knot 2 in $\mathrm{CDCl}_{3}$ at $298 \mathrm{~K}$; (f) 74 knot 2 in $\mathrm{C}_{2} \mathrm{D}_{2} \mathrm{Cl}_{4}$ at $393 \mathrm{~K}\left(500 \mathrm{MHz}^{\S}\right)$. The lettering corresponds to the proton labelling in Fig. 1. For full spectral assignments see SI section 1.3-1.6. ${ }^{\S} 393 \mathrm{~K}$ is outside the temperature range of our $600 \mathrm{MHz}$ NMR probe.

The analogous $\mathrm{Fe}(\mathrm{II})$ interwoven $3 \times 3$ grid, $\left[\mathrm{Fe}_{9} \mathbf{1}_{6}\right]\left(\mathrm{BF}_{4}\right)_{18}$, could be assembled from 1 and $\mathrm{Fe}\left(\mathrm{BF}_{4}\right)_{2} \cdot 6 \mathrm{H}_{2} \mathrm{O}$, but its formation required prolonged heating at $100{ }^{\circ} \mathrm{C}$. In both cases the use of tetrafluoroborate anions was crucial: interwoven grids did not form using a range of other $\mathrm{Zn}(\mathrm{II})$ and $\mathrm{Fe}(\mathrm{II})$ salts.

Variable temperature (VT) ${ }^{1} \mathrm{H}$ NMR in $\mathrm{C}_{2} \mathrm{D}_{2} \mathrm{Cl}_{4}$ showed interwoven grid $\left[\mathrm{Zn}_{9} \mathbf{1}_{6}\right]\left(\mathrm{BF}_{4}\right)_{18}$ to be stable up to at least $100{ }^{\circ} \mathrm{C}$. However, the grid could be spontaneously disassembled at room temperature by the addition of $\mathrm{N}, \mathrm{N}$-diisopropylethylamine, a relatively modest competitive ligand for $\mathrm{Zn}(\mathrm{II})$. The ${ }^{1} \mathrm{H}$ NMR spectrum of $\left[\mathrm{Fe}_{9} \mathbf{1}_{6}\right]\left(\mathrm{BF}_{4}\right)_{18}$ in $\mathrm{CD}_{3} \mathrm{CN}$ displays significant broadening of several sets of signals, indicative of the presence of some paramagnetic high spin $\mathrm{Fe}(\mathrm{II})$ ions. Electrospray ionization mass spectrometry $(E S I-M S)$ of $\left[\mathrm{Fe}_{9} \mathbf{1}_{6}\right]\left(\mathrm{BF}_{4}\right)_{18}$ and $\left[\mathrm{Zn}_{9} \mathbf{1}_{6}\right]\left(\mathrm{BF}_{4}\right)_{18}$ generated a series of multiply-charged ions, $\left\{\left[\mathrm{M}_{9} 1_{6}\right]\left(\mathrm{BF}_{4}\right)_{n}\right\}^{(18-n)+}(\mathrm{M}=\mathrm{Fe}$ or $\mathrm{Zn}, \mathrm{n}=4-8)$, corresponding to the grid minus various numbers of $\mathrm{BF}_{4}^{-}$ anions (SI sections 1.4 and 1.5).

Single crystals of $\left[\mathrm{Fe}_{9} \mathbf{1}_{6}\right]\left(\mathrm{BF}_{4}\right)_{18}$ suitable for structure determination by X-ray crystallography were obtained by slow diffusion of toluene into a solution of the grid in acetone. The X-ray structure of $\left[\mathrm{Fe}_{9} \mathbf{1}_{6}\right]\left(\mathrm{BF}_{4}\right)_{18}$ (SI section 1.8) forms the grid of the modelled $7_{4}$ knot structure shown in Fig. 3 , in which the disordered alkene-terminated chains are replaced by Merck Molecular Force Field (MMFF)modelled cyclized end groups. The X-ray structure confirmed the architecture as a $3 \times 3$ grid with each of the six ligands woven alternatively over or under another at nine co-planar $\mathrm{Fe}(\mathrm{II})$ ion crossing points. Four well-ordered $\mathrm{BF}_{4}{ }^{-}$anions are located in the square cavities formed between the weft and warp strands. The $\mathrm{B}-\mathrm{F}$ bonds of the $\mathrm{BF}_{4}{ }^{-}$anions point in the direction of the metal ions at the corners of the square with the fluorine atoms in close contact with the centres of the thiazole rings (Fig. 3d), stabilizing 
the assembly through a combination of charge-dipole and anion- $\pi$ interactions. ${ }^{40}$ The extended layered crystal structure of $\left[\mathrm{Fe}_{9} \mathbf{1}_{6}\right]\left(\mathrm{BF}_{4}\right)_{18}$ suggests a route to $2 \mathrm{D}$ woven molecular fabrics. ${ }^{41}$

The design of 1 is such that the alkene-terminated chains are sufficiently short that only adjacent strand ends on the $3 \times 3$ grid can reach each other to react through alkene metathesis, yet sufficiently long that conformations are available that avoid strain within the folded chains that could inhibit ring closure. Treatment of a dilute solution $(2 \mathrm{mM})$ of $\left[\mathrm{Zn}_{9} 1_{6}\right]\left(\mathrm{BF}_{4}\right)_{18}$ in $\mathrm{CH}_{2} \mathrm{Cl}_{2} / \mathrm{CH}_{3} \mathrm{NO}_{2} 3: 1$ with the $2^{\text {nd }}$ Generation Hoveyda-Grubbs catalyst ${ }^{42}\left(0.1\right.$ eq. per alkene) at $110^{\circ} \mathrm{C}$ under microwave irradiation for $1 \mathrm{~h}$ followed by demetallation with $\mathrm{Li}_{2} \mathrm{~S}$ gave a product mixture that ESI-MS (Supplementary Fig. 30) showed consisted largely of closed-loop species derived from two, four or six molecules of 1 (SI section 2.3). The three major closed-loop species were separated by gel permeation chromatography from linear oligomers bearing unreacted alkene end groups $(12 \%$ of alkenes present in the product mixture after metathesis were terminal; SI section 1.6). Longer reaction times did not lead to significant changes in the product distribution, until thermal degradation started to decrease the overall yield of isolable material.

The second most abundant species (37\% of the demetallated product mixture) was found to be the smallest cyclic product, macrocycle 3 , derived from two molecules of 1 . The ${ }^{1} \mathrm{H}$ NMR spectrum of 3 (Fig. 2c) is similar to that of the original building block, 1 (Fig. 2a), other than the absence of the $\mathrm{H}_{\mathrm{a} / \mathrm{a}^{\prime}}$ terminal alkene resonances and modest shielding of several protons (e.g. $\mathrm{H}_{\mathrm{r}}$ and $\mathrm{H}_{\mathrm{s}}$ ) due to aromatic stacking. As expected for an unknot macrocycle with no asymmetrical features, chiral high performance liquid chromatography (chiral HPLC) showed no evidence for 3 being chiral.

The most abundant product 4 , which makes up $56 \%$ of the demetallated product mixture, was shown by mass spectrometry to have a molecular mass corresponding to a closed-loop species derived from four molecules of 1 . The fragmentation pattern of the molecular ion (dethreading to half the mass once one macrocycle is broken open) and tandem mass spectrometry (Supplementary Fig. 13) indicated that $\mathbf{4}$ is a link (i.e., a catenane) made up of two interlocked molecules of $\mathbf{3}$. Chiral HPLC showed $\mathbf{4}$ to be a racemic mixture of enantiomers (Supplementary Fig. 15), despite the building blocks having no elements of Euclidean chirality (centres, axes, helices, etc.). At $298 \mathrm{~K}$ the ${ }^{1} \mathrm{H}$ NMR spectrum of 4 (Fig. 2d) is broader than that of 3 (Fig. 2c), but sharpens at higher temperatures (e.g. Spectrum 20), characteristic of the temperature-dependent behaviour of interlocked rings rotating about one another. The diastereotopic splitting of methylene group $\mathrm{H}_{k}$ confirms the chirality of 4 . Given the absence of other features that can impart chirality, molecular link $\mathbf{4}$ cannot be the singly-interlocked (Hopf) link, which is topologically achiral, but rather must be the topoisomeric inherently chiral doubly-interlocked (Solomon) link. ${ }^{38}$ 


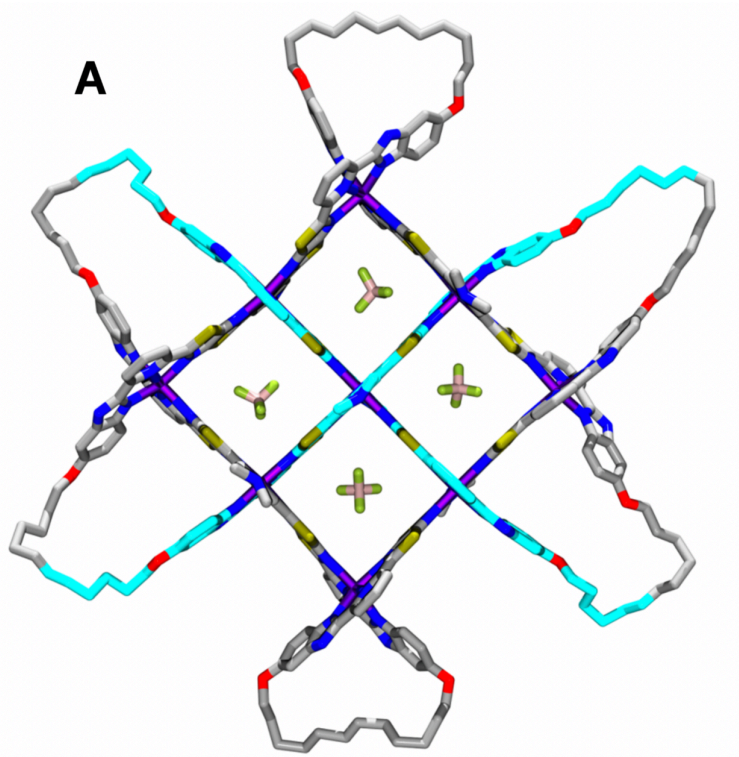

C

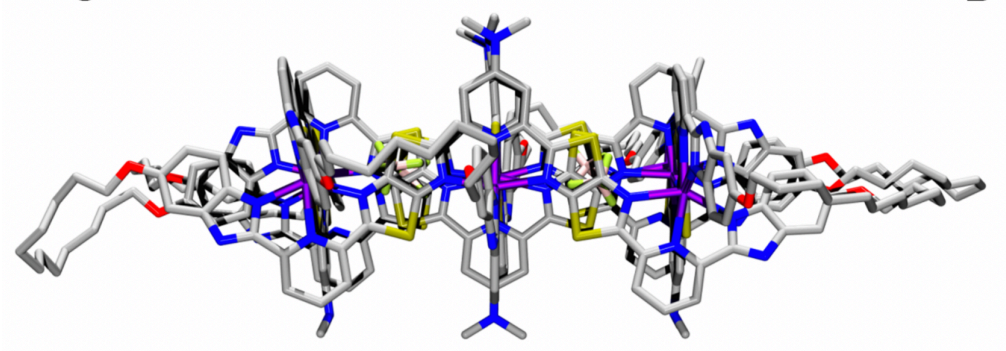

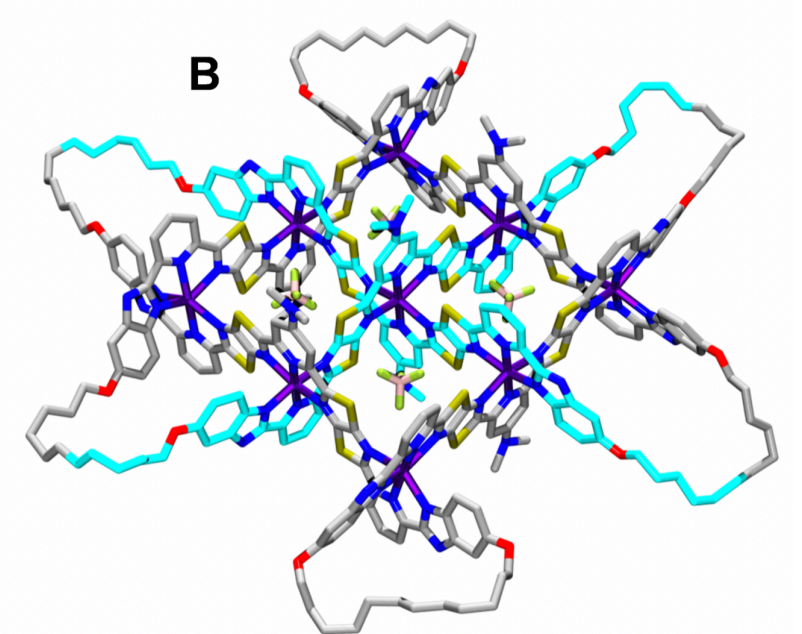

D

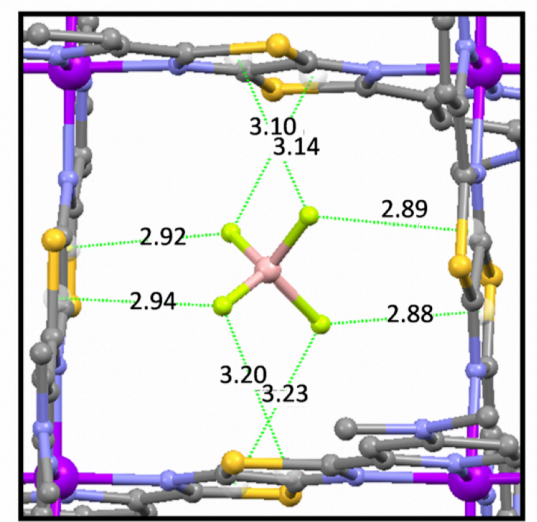

Fig. 3 | Structure of $7_{4}$ knot coordination complex $\left[\mathrm{Fe}_{9} 2\right]\left(\mathrm{BF}_{4}\right)_{18}$, based on the X-ray crystal structure of $\left[\mathrm{Fe}_{9} 1_{6}\right]\left(\mathrm{BF}_{4}\right)_{18}$ for the $3 \times 3$ grid region with MMFF-modelled cyclized end groups. (a) Viewed orthogonally to the plane of the nine $\mathrm{Fe}(\mathrm{II})$ ions. (b) Angled view showing the planarity of the weft and warp strands and the directionality of the anion ${ }^{\prime \prime} \pi$ and anion- $\mathrm{Fe}(\mathrm{II})$ interactions of the $\mathrm{BF}_{4}{ }^{-}$ templates. (c) Viewed along the plane of the $\mathrm{Fe}(\mathrm{II})$ ions. (d) One of the square cavities formed between the criss-crossed strands in the X-ray crystal structure of $\left[\mathrm{Fe}_{9} \mathbf{1}_{6}\right]\left(\mathrm{BF}_{4}\right)_{18}$, showing the $\mathrm{B}-\mathrm{F}$ bonds pointing in the direction of the metal ions and close anion $\cdots \pi$ contacts between the fluorine atoms and the centres of thiazole rings: $F_{3} B-F \cdots$ centroid distances $2.88-3.23 \AA$. Carbon atoms are coloured light grey or turquoise. Nitrogen atoms are blue; iron, purple; oxygen, red; boron, pink; fluorine, green; sulfur, yellow. Other anions, the isopentyl chains and hydrogen atoms not shown for clarity.

The highest molecular mass product isolated forms $7 \%$ of the demetallated mixture of cyclic products and was shown by mass spectrometry to have a molecular mass corresponding to a closed-loop species derived from six molecules of 1 . Remetallation of this material with $\mathrm{Zn}\left(\mathrm{BF}_{4}\right)_{2} \cdot 6 \mathrm{H}_{2} \mathrm{O}$ in $\mathrm{CHCl}_{3}: \mathrm{CH}_{3} \mathrm{CN}$ (1:1) formed $\left[\mathrm{Zn}_{9} 2\right]\left(\mathrm{BF}_{4}\right)_{18}$ (see Supplementary Fig. 18). The ${ }^{1} \mathrm{H}$ NMR spectrum of $\left[\mathrm{Zn}_{9} 2\right]\left(\mathrm{BF}_{4}\right)_{18}\left(\mathrm{SI}\right.$ section 1.7) is related to that of the parent $3 \times 3$ grid $\left[\mathrm{Zn}_{9} \mathbf{1}_{6}\right]\left(\mathrm{BF}_{4}\right)_{18}$, but is broader, lacks the terminal alkene protons, and the proton environments are less well resolved. The open $3 \times 3$ grid has $D_{2 d}$ symmetry but joining adjacent strands on the grid to form the metal-coordinated $7_{4}$ knot forms two nugatory crossings ${ }^{2}$ that changes the number of different chain environments. The ${ }^{1} \mathrm{H}$ NMR spectrum of the demetallated $7_{4} \mathrm{knot}, 2$, at room temperature in $\mathrm{CDCl}_{3}$ is extremely broad (Fig. 2e). However, at $393 \mathrm{~K}$ in $\mathrm{C}_{2} \mathrm{D}_{2} \mathrm{Cl}_{4}$ the signals sharpen significantly and become well resolved (Fig. 2f), with each distinct type of proton $\left(\mathrm{H}_{\mathrm{b-j}, \mathrm{l}-\mathrm{r}}\right)$ giving rise to a single set of signals (the nugatory crossings only persist in the presence of metal ions), a feature characteristic of fast reptation ${ }^{43}$ of the 258-atom-long knotted chain on the NMR timescale at this elevated temperature. Like Solomon links, 74 knots are topologically chiral, leading to diastereotopic $\mathrm{H}_{\mathrm{k}}$ protons in $\mathbf{2}$ (Fig. 2f). However, $\mathbf{2}$ was insufficiently soluble in suitable solvents for separation of the enantiomers by chiral HPLC.

The presence (and the amounts formed) of different cyclized products from the $3 \times 3$ grid can be rationalized from consideration of the mechanism of formation of the $7_{4}$ knot (Fig. 4; SI section 2.3). Although alkene metathesis can be under thermodynamic control in certain circumstances, ${ }^{44}$ under the 
conditions used here each joining reaction is essentially irreversible. Two different types of intracomplex olefin metathesis reactions occur on the grid: one connects strand ends at a corner of the grid ('corner join'); the other type connects the ends of two adjacent strands along a grid edge ('edge join'). Molecular modelling (Fig. 3) shows that the corner joins are more strained than the edge joins leading to reactions that connect strand ends along edges proceeding more rapidly than corner-forming connections. Under the high dilutions employed inter-grid reactions are rare; there was no evidence for grid dimers forming under these conditions by mass spectrometry.

Once one edge join is formed (shown on the 'north side' of the grid in intermediate I; Fig. 4), then alkene metathesis between adjacent strand ends on the opposite side of the grid can occur in two inequivalent ways (to form isomers IIA or IIB). If further edge joins on the east-west sides of IIA occur with the regiochemistry shown for IIIA, then the four remaining strand ends can form two corner joins leading to the $7_{4}$ knot. However, if any of the edge joins occur with a different relative regiochemistry to IIIA then some strand ends are left without an adjacent partner with which to form a corner join and the $7_{4} \mathrm{knot}$ cannot form. If strand connections on one side of the grid do not affect the regiochemistry of alkene metathesis on another side then the maximum theoretical yield of the $7_{4}$ knot is $12.5 \%$. Experimentally, we isolated 2 as $7 \%$ of the mixture of closed-loop products. Exposure of the product mixture from grid alkene metathesis to fresh catalyst at different concentrations did not change the product distribution. If the products were in dynamic exchange, the yield of 74 knot could potentially increase as only its formation liberates the maximum number (six) of ethene molecules from intra-grid reactions.

The only other cyclic products that can result from intra-grid olefin metathesis are macrocycle 3 and Solomon link 4. These were isolated experimentally as 37 and $56 \%$, respectively, of the closed-loop products. Without the ability to re-open incorrectly formed connections between adjacent strands on the grid, neither $\mathbf{3}$ nor $\mathbf{4}$ can act as intermediates to a 74 knot. Note that a Hopf link topology cannot arise from edge and corner joins on the interwoven $3 \times 3$ grid, nor can an unknot macrocycle or five-crossing Whitehead link be formed from connections between all six ligands on the grid. 


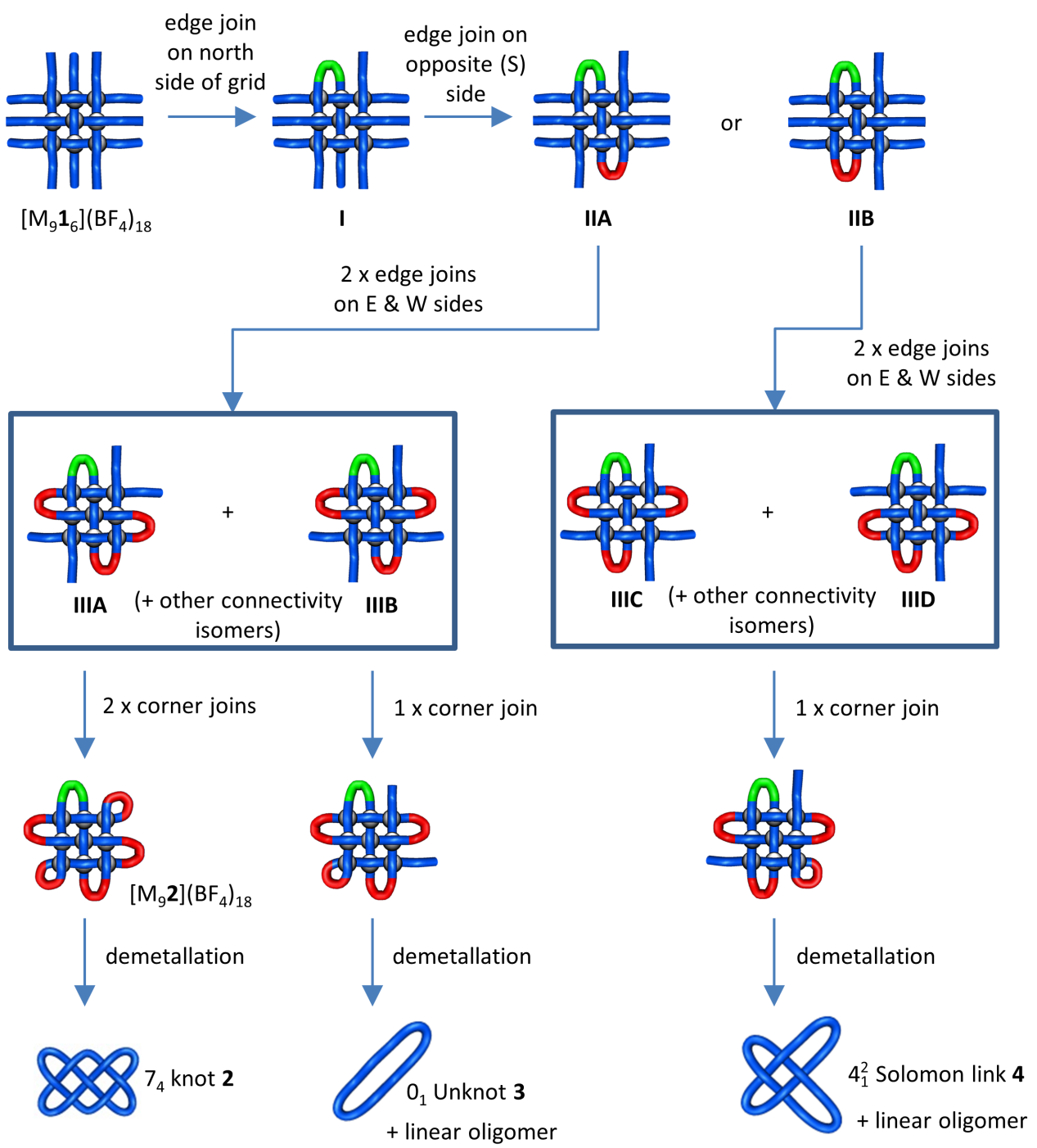

Fig. 4 Mechanism of formation of unknot macrocycle 3, Solomon link 4 and $7_{4}$ knot 2 by connecting strand ends within a $3 \times 3$ interwoven grid, $\left[\mathrm{M}_{9} 1_{6}\right]\left(\mathrm{BF}_{4}\right)_{18}(\mathrm{M}=\mathrm{Zn}(\mathrm{II}), \mathrm{Fe}(\mathrm{II}))$. If edge joins form more rapidly (and under kinetic control) than corner joins, and strand connections on one side of the grid do not affect the regiochemistry of connections on another side, then the maximum theoretical yield of the 74 knot is $12.5 \%$ ( $\mathrm{SI}$ section 2.3 ).

\section{Conclusions}

Originally unanticipated anion template interactions enable the quantitative, metal-ion-coordination driven, weaving of six ligand strands within a discrete molecular layer. Intra-grid closure of the chain ends of the resulting $3 \times 3$ interwoven grid can be used to generate a $7_{4} \mathrm{knot}$, with kinetically controlled connections producing an unknot macrocycle and Solomon link as byproducts of the two-step assembly process. Fundamental elements of topology have previously been targeted to exemplify new strategies in synthesis, including the first examples of small-molecule Borromean rings, ${ }^{45}$ pentafoil knots ${ }^{15}$ and a Star of David catenane ${ }^{46}$. The 74 knot is a basic motif of Celtic knotting, the smallest Chinese knot, and is one of the eight auspicious symbols (the Ashtamangala) common to many Eastern religions and philosophies, where it represents the union of wisdom and method. The practical significance of its preparation in molecular form include the lessons learnt from its assembly (ligand design, metal and anion template weaving, mechanism of end-joining, etc.), which open the way for the bottom-up, coordination-driven assembly of polymer chains woven in two-dimensions ${ }^{47-51}$ and other knotted and entangled molecules and materials.

\section{References}

1. Ashley, C. The Ashley Book of Knots (Doubleday, New York, 1994). 
2. Fielden, S. D. P., Leigh, D. A. \& Woltering, S. L. Molecular knots. Angew. Chem. Int. Ed. 56, 11166-11194 (2017).

3. Frank-Kamenetskii, M. D., Lukashin, A. V. \& Vologodskii, A. V. Statistical mechanics and topology of polymer chains. Nature 258, 398-402 (1975).

4. Lim, N. C. H. \& Jackson, S. E. Molecular knots in biology and chemistry. J. Phys.: Condens. Matter 27, 354101 (2015).

5. Saitta, A. M., Soper, P. D., Wasserman, E. \& Klein, M. L. Influence of a knot on the strength of a polymer strand. Nature 399, 46-48 (1999).

6. Katsonis, N., et al. F. Knotting a molecular strand can invert macroscopic effects of chirality. Nat. Chem. (2020) http://dx.doi.org/10.1038/s41557-020-0517-1.

7. Benyettou, F. et al. Potent and selective in vitro and in vivo antiproliferative effects of metal-organic trefoil knots. Chem. Sci. 10, 5884-5892 (2019).

8. Ayme, J.-F. et al. Strong and selective anion binding within the central cavity of molecular knots and links. J. Am. Chem. Soc. 137, 9812-9815 (2015).

9. Bilbeisi, R. A. et al. [C-H - a anion] interactions mediate the templation and anion binding properties of topologically non-trivial metal-organic structures in aqueous solutions. Chem. Sci. 7, 2524-2532 (2016).

10. Marcos, V. et al. Allosteric initiation and regulation of catalysis with a molecular knot. Science 352 , 1555-1559 (2016).

11. Gil-Ramírez, G. et al. Tying a molecular overhand knot of single handedness and asymmetric catalysis with the corresponding pseudo- $D_{3}$-symmetric trefoil knot. J. Am. Chem. Soc. 138, 1315913162 (2016).

12. Dietrich-Buchecker, C. O. \& Sauvage, J.-P. A synthetic molecular trefoil knot. Angew. Chem. Int. Ed. Engl. 28, 189-192 (1989).

13. Guo, J., Mayers, P. C., Breault, G. A. \& Hunter, C. A. Synthesis of a molecular trefoil knot by folding and closing on an octahedral coordination template. Nat. Chem. 2, 218-222 (2010).

14. Barran, P. E. et al. Active metal template synthesis of a molecular trefoil knot. Angew. Chem. Int. Ed. 50, 12280-12284 (2011).

15. Ayme, J.-F. et al. A synthetic molecular pentafoil knot. Nat. Chem. 4, 15-20 (2012).

16. Ayme, J.-F. et al. Lanthanide template synthesis of a molecular trefoil knot. J. Am. Chem. Soc. 136, 13142-13145 (2014).

17. Zhang, L. et al. A molecular trefoil knot from a trimeric circular helicate. J. Am. Chem. Soc. 140, 4982-4985 (2018).

18. Danon, J. J. et al. Braiding a molecular knot with eight crossings. Science 355, 159-162 (2017).

19. Zhang, L. et al. Stereoselective synthesis of a composite knot with nine crossings. Nat. Chem. 10 , 1083-1088 (2018).

20. Leigh, D. A., et al. Tying different knots in a molecular strand. Nature 584, 562-568 (2020).

21. Segawa, Y. et al. Topological molecular nanocarbons: All-benzene catenane and trefoil knot. Science 365, 272-276 (2019).

22. Safarowsky, O., Nieger, M., Fröhlich, R. \& Vögtle, F. A molecular knot with twelve amide groupsone-step synthesis, crystal structure, chirality. Angew. Chem. Int. Ed. 39, 1616-1618 (2000).

23. Feigel, M., Ladberg, R., Engels, S., Herbst-Irmer, R. \& Fröhlich, R. A trefoil knot made of amino acids and steroids. Angew. Chem. Int. Ed. 45, 5698-5702 (2006).

24. Kim, D. H. et al. Coordination-driven self-assembly of a molecular knot comprising sixteen crossings. Angew. Chem. Int. Ed. 57, 5669-5673 (2018).

25. Leigh, D. A., Lemonnier, J.-F. \& Woltering, S. L. Comment on "Coordination-driven self-assembly of a molecular knot comprising sixteen crossings". Angew. Chem. Int. Ed. 57, 12212-12214 (2018).

26. Inomata, Y., Sawada, T. \& Fujita, M. Metal-peptide torus knots from flexible short peptides. Chem 6, 294-303 (2020).

27. Ponnuswamy, N., Cougnon, F. B. L., Clough, J. M., Pantoş, G. D. \& Sanders, J. K. M. Discovery of an organic trefoil knot. Science 338, 783-785 (2012).

28. Ponnuswamy, N., Cougnon, F. B. L., Pantoş, G. D. \& Sanders, J. K. M. Homochiral and meso figure eight knots and a Solomon link. J. Am. Chem. Soc. 136, 8243-8251 (2014).

29. Cougnon, F. B. L., Caprice, K., Pupier, M., Bauza, A. \& Frontera, A. A strategy to synthesize molecular knots and links using the hydrophobic effect. J. Am. Chem. Soc. 140, 12442-12450 (2018). 30. Forgan, R. S., Sauvage, J.-P. \& Stoddart, J. F. Chemical topology: complex molecular knots, links, and entanglements. Chem. Rev. 111, 5434-5464 (2011).

31. Ayme, J.-F., Beves, J. E., Campbell, C. J. \& Leigh, D. A. Template synthesis of molecular knots. Chem. Soc. Rev. 42, 1700-1712 (2013). 
32. Sauvage. J.-P. From chemical topology to molecular machines (Nobel Lecture), Angew. Chem. Int. Ed. 56, 11080-11093 (2017).

33. Marenda, M., Orlandini, E. \& Micheletti, C. Discovering privileged topologies of molecular knots with self-assembling models. Nat. Commun. 9, 3051 (2018).

34. Alexander, J. W. \& Briggs, G. B. On types of knotted curves. Ann. Math. 28, 562-586 (1926).

35. Bucka, A. \& Stasiak, A. Construction and electrophoretic migration of single-stranded DNA knots and catenanes. Nucleic Acids Res. 30, e24 (2002).

36. Ruben, M., Rojo, J., Romero-Salguero, F. J., Uppadine, L. H. \& Lehn, J.-M. Grid-type metal ion architectures: functional metallosupramolecular arrays. Angew. Chem. Int. Ed. 43, 3644-3662 (2004).

37. Dawe, L. N., Abedin, T. S. M. \& Thompson, L. K. Ligand directed self-assembly of polymetallic [n $\times$ n] grids: rational routes to large functional molecular subunits? Dalton Trans. 1661-1675 (2008).

38. Beves, J. E., Danon, J. J., Leigh, D. A., Lemonnier, J.-F. \& Vitorica-Yrezabal, I. J. A Solomon link through an interwoven molecular grid. Angew. Chem. Int. Ed. 54, 7555-7559 (2015).

39. Danon, J. J., Leigh, D. A., Pisano, S., Valero, A. \& Vitorica-Yrezabal, I. J. A six-crossing doubly interlocked [2]catenane with twisted rings, and a molecular granny knot. Angew. Chem. Int. Ed. 57, 13833-13837 (2018).

40. Bianchi, A., Bowman-James, K. \& Garcia, E. Supramolecular Chemistry of Anions (Wiley-VCH, New York, 1997).

41. August, D. P. et al. A Woven 2D Molecular Fabric. submitted for publication.

42. Garber, S. B., Kingsbury, J. S., Gray, B. L. \& Hoveyda, A. H. Efficient and recyclable monomeric and dendritic Ru-based metathesis catalysts. J. Am. Chem. Soc. 122, 8168-8179 (2000).

43. De Gennes, P. G. Reptation of a polymer chain in the presence of fixed obstacles. J. Chem. Phys. 55, 572-571 (1971).

44. Kidd, T. J., Leigh, D. A. \& Wilson, A. J. Organic "magic rings" - The hydrogen bond-directed assembly of catenanes under thermodynamic control. J. Am. Chem. Soc. 121, 1599-1600 (1999).

45. Chichak, K. S. et al. Molecular Borromean rings. Science 304, 1308-1312 (2004).

46. Leigh, D. A., Pritchard, R. G. \& Stephens, A. J. A Star of David Catenane. Nat. Chem. 6, 978-982 (2014).

47. Hubin, T. J. \& Busch, D. H. Template routes to interlocked molecular structures and orderly molecular entanglements. Coord. Chem. Rev. 200-202, 5-52 (2000).

48. Cockriel, D. L., et al. The design and synthesis of pyrazine amide ligands suitable for the "tiles" approach to molecular weaving with octahedral metal ions. Inorg. Chem. Commun. 11, 1-4 (2008). 49. Wadhwa, N. R., Hughes, N. C., Hachem, J. A. \& Mezei, G. Metal-templated synthesis of intertwined, functionalized strands as precursors to molecularly woven materials. RSC Adv. 6, 1143011440 (2016).

50. Wang, Z. et al. Molecular weaving via surface-templated epitaxy of crystalline coordination networks. Nat. Commun. 8, 14442 (2017).

51. Lewandowska, U. et al. A triaxial supramolecular weave. Nat. Chem. 9, 1068-1072 (2017).

\section{Acknowledgements}

We thank Jonathon E. Beves (now University of New South Wales) for early ligand designs for this project; the Engineering and Physical Sciences Research Council (EPSRC; EP/P027067/1), the European Research Council (ERC; Advanced Grant No. 786630), the China 1000 Talents Plan and East China Normal University for funding; the EPSRC National Mass Spectrometry Service Centre (Swansea, UK) for high-resolution mass spectrometry; the Diamond Light Source (UK) for synchrotron beam time on I19 (XR029); networking contributions from the COST Action CA17139, EUTOPIA; and Alberto Valero for the video of the rotating $7_{4}$ knot structure. D.A.L. is a Royal Society Research Professor.

\section{Author Contributions}

J.J.D., S.D.P.F., J.F.L. and S.L.W. carried out the synthesis and characterization studies. G.F.S.W. solved the crystal structure. D.A.L. directed the research. All authors contributed to the analysis of the results and the writing of the manuscript.

\section{Competing Interests Statement}

The authors declare no competing interests. 


\section{Methods}

\section{Synthesis of endless knot 2, Solomon link 4 and macrocycle 3 by olefin metathesis and demetallation of $3 \times 3$ interwoven grid}

$\left[\mathrm{Zn}_{9} \mathbf{1}_{6}\right]\left(\mathrm{BF}_{4}\right)_{18}(360 \mathrm{mg}, 40 \mu \mathrm{mol})$ or $\left[\mathrm{Fe}_{9} \mathbf{1}_{6}\right]\left(\mathrm{BF}_{4}\right)_{18}(360 \mathrm{mg}, 40 \mu \mathrm{mol})$ and Hoveyda-Grubbs $2^{\text {nd }}$ generation catalyst ( $30 \mathrm{mg}, 48 \mu \mathrm{mol}, 0.10$ eq per free olefin) were added to a $20 \mathrm{~mL}$ microwave vial equipped with a magnetic stirrer. The vial was sealed and inerted via three cycles of vacuum/nitrogen purging. Dry and degassed (nitrogen bubbling) $\mathrm{CH}_{2} \mathrm{Cl}_{2}(15 \mathrm{~mL})$ and $\mathrm{CH}_{3} \mathrm{NO}_{2}(5.0 \mathrm{~mL}$ ) were added via syringe and the mixture sonicated until all solids had dissolved (approx. 30 seconds). The vial containing the reaction mixture was heated to $110{ }^{\circ} \mathrm{C}$ under microwave irradiation for 90 minutes (approx. $6.0 \mathrm{bar}$ of pressure was generated within the vial over the course of the reaction). After the mixture was cooled to room temperature, ethyl vinyl ether $(3.0 \mathrm{~mL})$ was added. The mixture was stirred for 5.0 minutes and subsequently transferred to a round-bottom flask. The solvents were removed under reduced pressure and the residue dissolved in $\mathrm{CH}_{3} \mathrm{CN}(5.0 \mathrm{~mL})$. Diethyl ether $(25 \mathrm{~mL})$ was added to afford a yellow/brown precipitate, which was isolated by vacuum filtration over celite. The solid was washed with fresh diethyl ether $(25 \mathrm{~mL})$, and redissolved in $\mathrm{CH}_{3} \mathrm{CN}(25 \mathrm{~mL}) . \mathrm{CHCl}_{3}(25 \mathrm{~mL})$ was added to the solution, followed by water $(5.0 \mathrm{~mL})$ and $\mathrm{Li}_{2} \mathrm{~S}(30 \mathrm{mg}, 0.65 \mathrm{mmol})$ when using $\left[\mathrm{Zn}_{9} 1_{6}\right]\left(\mathrm{BF}_{4}\right)_{18}$ or $\mathrm{Na}_{4} \mathrm{EDTA}(380 \mathrm{mg}, 1.0$ $\mathrm{mmol}$ ) when using $\left[\mathrm{Fe}_{9} \mathbf{1}_{6}\right]\left(\mathrm{BF}_{4}\right)_{18}$. The mixture was stirred vigorously for $1.0 \mathrm{~h}$, after which the mixture was partitioned between $\mathrm{CHCl}_{3}(250 \mathrm{~mL})$ and water $(250 \mathrm{~mL})$ and the organic phase separated. The aqueous phase was further extracted with $\mathrm{CHCl}_{3}(3 \times 100 \mathrm{~mL})$ and the combined organics washed with brine $(250 \mathrm{~mL})$ and dried $\left(\mathrm{Na}_{2} \mathrm{SO}_{4}\right)$ before concentrating to dryness under reduced pressure. The resulting orange solid was redissolved in $\mathrm{CHCl}_{3}$ and passed over a plug of silica, eluting with $\mathrm{CHCl}_{3} / \mathrm{MeOH}$ 9:1 until the liquors were colourless. Mass recovery of organic material with respect to input of ligand 1 was $140 \mathrm{mg}$ after reconcentration, approximating to $50 \%$ when using either $\left[\mathrm{Zn}_{9} \mathbf{1}_{6}\right]\left(\mathrm{BF}_{4}\right)_{18}$ or $\left[\mathrm{Fe}_{9} \mathbf{1}_{6}\right]\left(\mathrm{BF}_{4}\right)_{18}$. The mixture was purified by a combination of recycling GPC (eluent $\mathrm{CHCl}_{3} / \mathrm{Et}_{3} \mathrm{~N}$ 99.5:0.5) and preparative TLC $\left(\mathrm{SiO}_{2}, \mathrm{CH}_{2} \mathrm{Cl}_{2} / \mathrm{MeOH} / \mathrm{Et}_{3} \mathrm{~N}\right.$ 92:7:1) to afford 2, 4 and 3 as bright yellow powders in a 7:56:37 ratio.

\section{Data Availability Statement}

The data that support the findings of this study are available within the paper and its Supplementary Information, or are available from the Mendeley data repository (https://data.mendeley.com/) under doi:10.17632/g5b854f68w.1. CCDC-2022144 contains the supplementary crystallographic data. These data can be obtained free of charge via www.ccdc.cam.ac.uk/conts/retrieving.html (or from the Cambridge Crystallographic Data Centre, 12 Union Road, Cambridge CB21EZ, UK; fax: (+44)1223336-033; or deposit@ccdc.cam.ac.uk).

\section{Supporting Information:}

Experimental procedures and characterization data

Supplementary Discussion

Supplementary Figures 1-40

Supplementary Tables 1-3

Spectra 1-21

Supplementary References 1-21

Movie of endless $7_{4}$ knot based on the X-ray crystal structure of the $3 \times 3$ grid with Merck Mechanics Force Field (MMFF)-modelled cyclized end groups. 